\title{
SYNDEPOSITIONAL DEFORMATION IN THE KURKISELKÄ ESKER, KIIMINKI, FINLAND
}

\begin{abstract}
Risto Aario
Aario, Risto 1971: Syndepositional deformation in the Kurkiselkä esker, Kiiminki, Finland. Bull. Geol. Soc. Finland 43, 163-172.

Syndepositional and metadepositional deformation structures from an esker section in Kiiminki, Finland, are described and discussed. The small folds are suggested to be a response of cohesive, hydroplastic material to the drag of turbulent flow, and the accompanying differential pressure conditions. The data indicate a rippling mechanism. The small folds have a transition into more complicated structures derived mainly from syndepositional or metadepositional horizontal movements, apparently in part gravity-induced, which operated contemporaneously with the rippling mechanism.

The syndepositional deformation structures of the category described are rather common in the Oulu vicinity, probably due to the widespread occurrence of water-laid deposits composed of fine sand, a grain size that favours this kind of deformation. They can readily be confused with deformation structures of other origin, which exist in juxtaposition within the same area.
\end{abstract}

Risto Aario, Department of Geology, University of Oulu, Finland.

\section{Introduction}

Various kinds of deformational structures frequently exist in the small esker ridges along the Bothnian coast in the vicinity of Oulu (R. Aario 1971). The origin of these structures, however, is often difficult to decipher; in some cases the environment under conditions of icecontact, and overriding ice have been responsible (ibid.). An esker section from this area with syndepositional deformation will be described and discussed in this paper. In the writer's experience the structures described below are not uncommon in Finnish Pleistocene exposures; references in literature, however, are lacking. The purpose of this note, therefore, is to call atten- tion to their existence in Finland and to their paleoenvironmental significance.

\section{Location}

The Kurkiselkä esker ridge lies in Kiiminki, about $23 \mathrm{~km}$ northeast of Oulu (Fig. 1). The esker is low and narrow and closely resembles the one from Ylikiiminki (ibid.) and a similar ice-contact origin can be suggested. The face studied with its exposed deformation structures, is located at the northeastern slope of the northwest - southeast oriented ridge. It is at the present time being removed by quarrying operations, but several lacquer peels have been pre- 


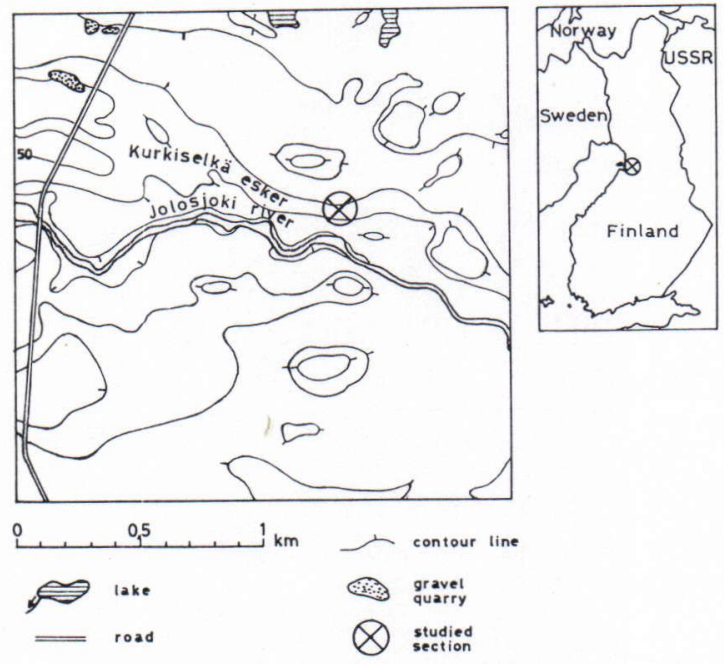

Fig. 1. Index map showing location of the study site.

paired (Aario and Viitanen 1970) and they are preserved in the collections of the Department of Geology, University of Oulu, Finland.

\section{Description of the sequence}

In the following description of the sequence of sedimentary structures the ripple lamination terminology of Jopling and Walker (1968) and the grain size classes defined by Atterberg will be used. The main characteristics of the southwest facing section, approximately $1.4 \mathrm{~m}$ high and $14 \mathrm{~m}$ long, are sketched in Fig. 2 and some representative details are shown in photographs (Figs. 3-7).

The sequence is nearly undisturbed in the part of the section represented by $2 \mathrm{~m}$ on the abscissa of the diagrammatic sketch. This part, from c to $f$, is shown in a photograph (Fig. 3). The lowest horizon (a) consists of massive coarse sand overlain by horizontally laminated fine sand. Unit b mainly consists of fine sand with grain size diminishing upwards, but contains also some silty, more cohesive laminae on top. The type of lamination changes in conjunction

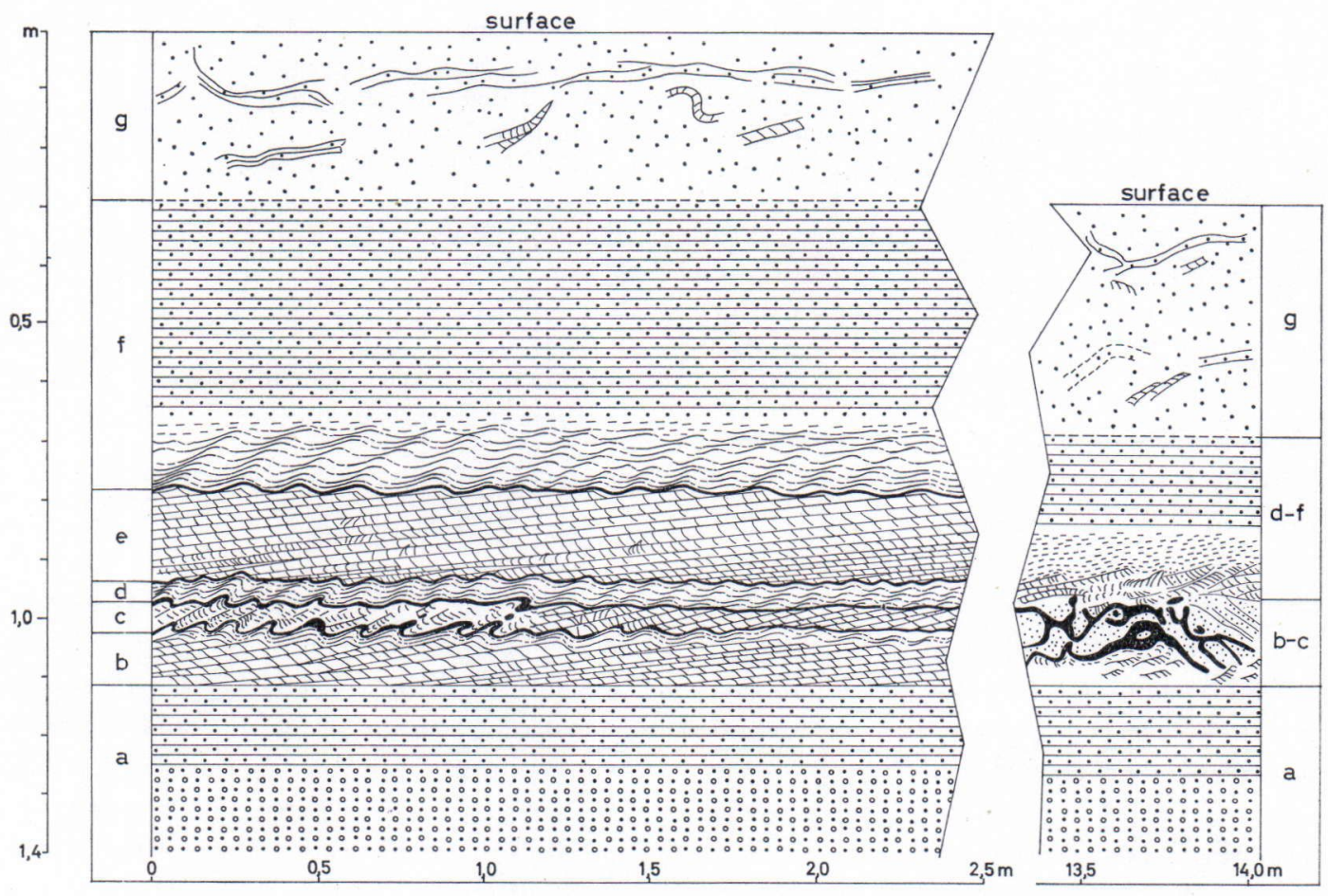

Fig. 2. A diagrammatic sketch of the studied section showing the main distribution of the structures discussed in text. More details are shown in the photographs corresponding to figures $3-7$. The sketch is based on field data, the photographs represent lacquer peels. 


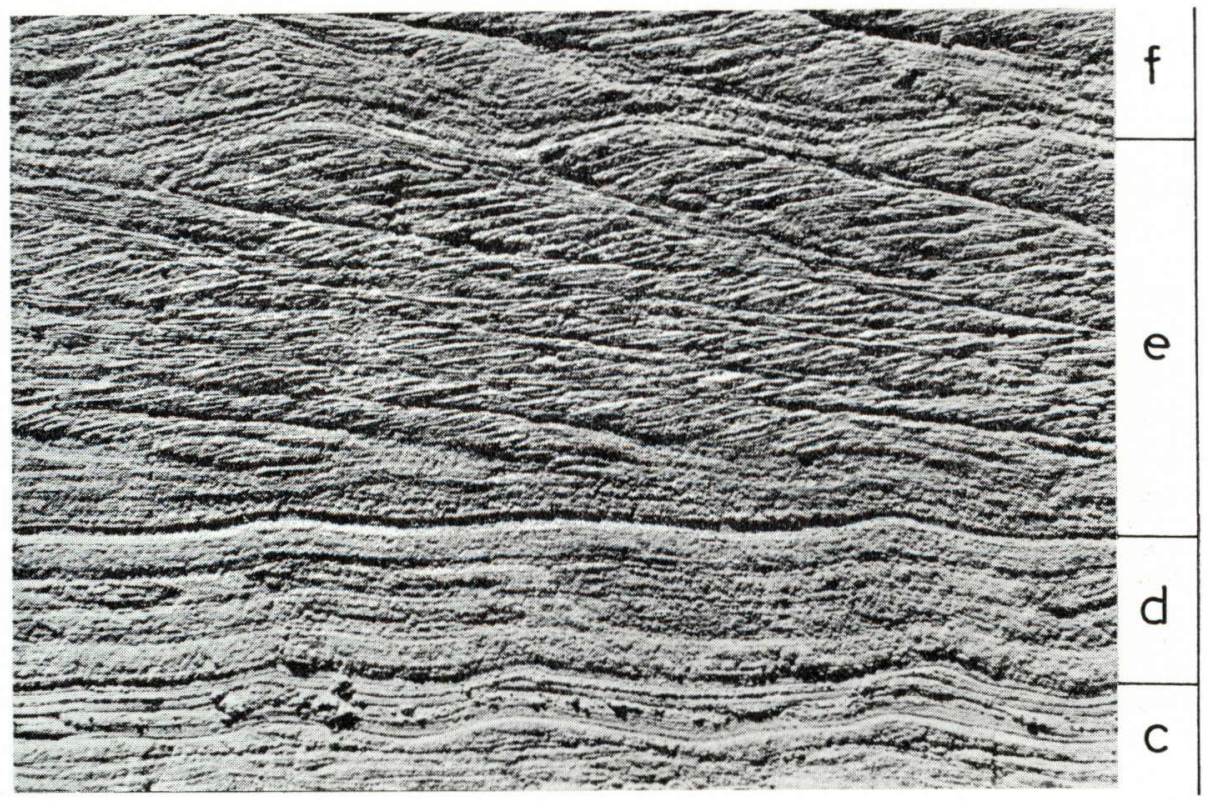

$\stackrel{10}{0} \quad 20 \mathrm{~cm}$

Fig. 3. A lacquer peel of units $\mathrm{c}$ to $\mathrm{f}$ from the undisturbed area of the section at 2 meters on the abscissa of the sketch. Current from right to left. Closer description in text.
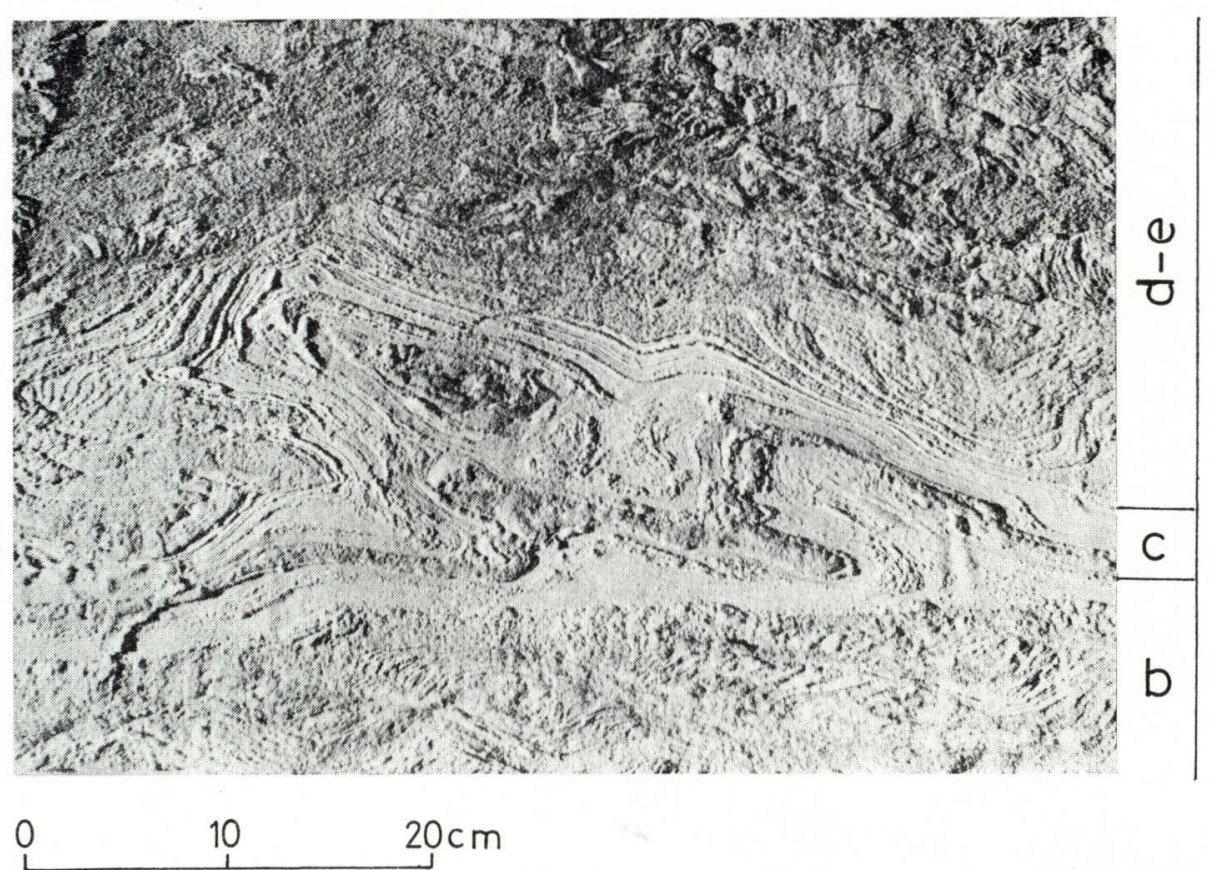

Fig. 4. A lacquer peel from the strongly disturbed part of the section at 13.5 meters on the abscissa of the sketch. The face seen in the photograph owes its configuration both to the small scale deformation of the laminae themselves and to the nearly vertical position of some parts 


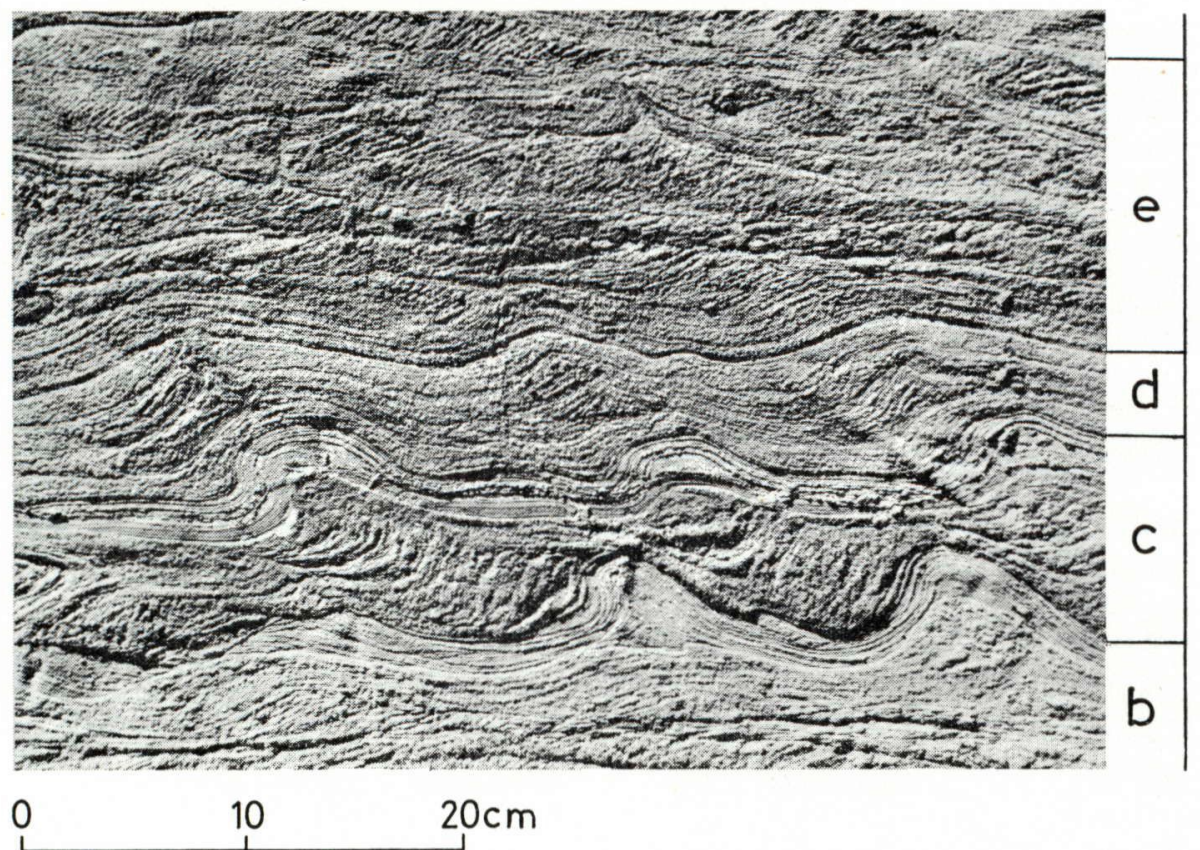

Fig. 5. A lacquer peel from the arca of less intensive deformation at 0.3 meters on the abscissa of the sketch. The first sandy lees of units $\mathrm{c}$ to $\mathrm{d}$ were deposited behind the ripple crests or the compound ripple-fold crests. The current was from right to left. Later they were often oversteepened and evin overturned by the further deformation process. The fold crests at the top of unit $\mathrm{c}$ and the subsequent ripple crests of unit $\mathrm{d}$ are in superposition. The intensity of the deformative oversteepening of the lees decreases upwards in unit d. A minute squeezed-up structure is visible in the photograph close to the middle of unit e.

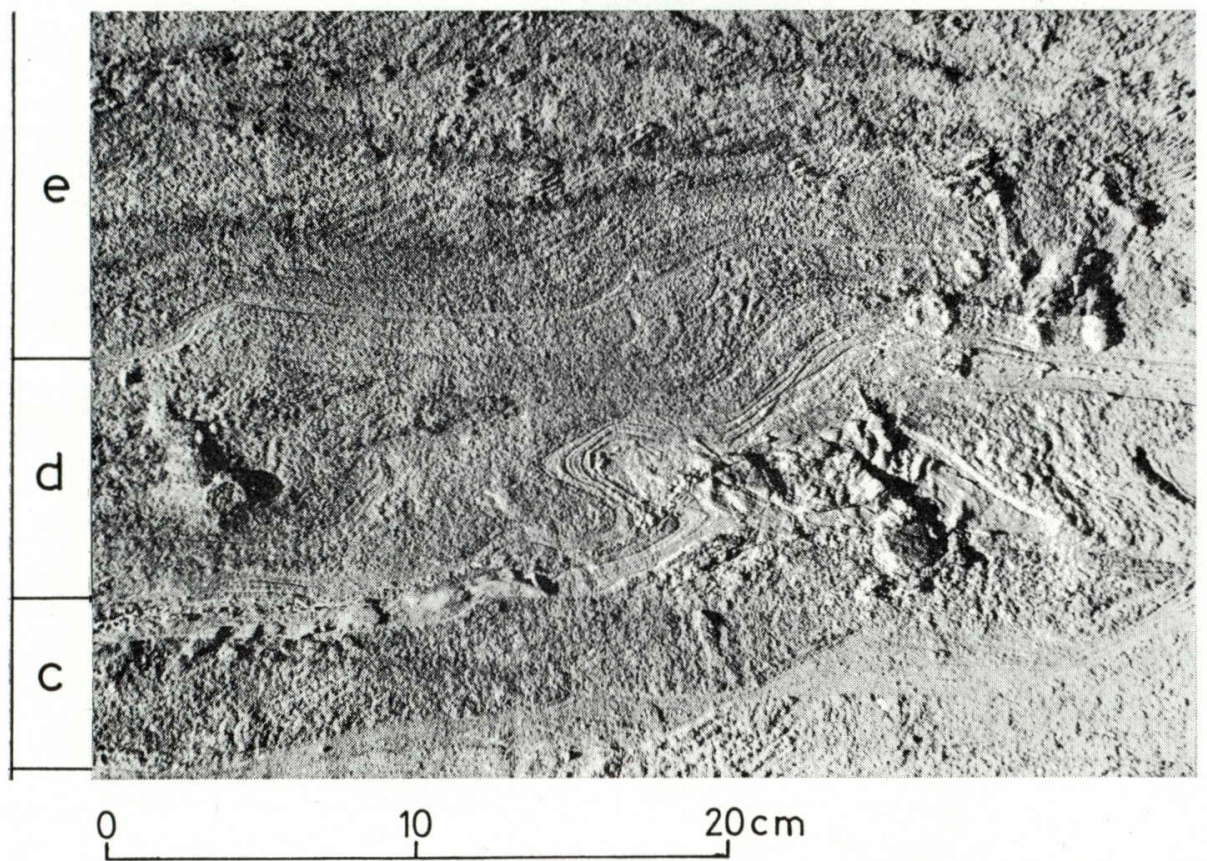

Fig. 6. A lacquer peel from the area at $1 \mathrm{~m}$ on the abscissa of the sketch. The ripple lamination of unit $d$ has adjusted to the underlying deformative bottom relief showing the pre-existence of deformation to the deposition of unit $\mathrm{d}$. 
with grain size from the ripple-drift cross-lamination approaching type $A$, through type $B$ (Jopling and Walker 1968), into horizontal or gently undulating lamination, approaching the sinusoidal type, at the top. Unit $\mathrm{c}$ is closely similar to unit b. Units $\mathrm{d}$ and e are both mainly composed of fine sand with only a thin veneer of fine cohesive material at the top. The fine sand of unit d generally shows ripple-drift crosslamination close to type B (not in Fig. 3), and that of unit e shows mainly the type A rippledrift cross-lamination. Unit $f$, also of fine sand, begins with cross-lamination approaching type B, followed by a horizontally laminated part above. The uppermost, disturbed surface part of the section constitutes unit g.

The changes in grain size and lamination show fluctuations in the hydrodynamic regime of the current, which deposited the sequence. The flow was predominantly from SSW (about $195^{\circ}$ ) as evidenced by measured ripple marks. A reverse orientation, however, was measured from the thin interbedded lee-side laminae within the layer of fine material at the top of unit c. It can be seen also in Fig. 3 as a slight reverse migration of ripple crests. The reverse flow is possibly due to a backflow effect, an interpretation discussed more thoroughly by the present author in a current study of the horizontal pattern of ripple marks in a deltaic paleoenvironment (see also Kuenen 1953 b, p. 31).

Especially at $0.3 \mathrm{~m}, 1.0 \mathrm{~m}$, and $13.5-14 \mathrm{~m}$ on the abscissa of the diagrammatic sketch (Fig. 2), deformed laminae exist in the sequence, mainly restricted to units $\mathrm{b}$ to $\mathrm{d}$. They were examined from horizontal and vertical sections as well as from exposed bedding surfaces. The vertical cuts are shown in photographs corresponding to figures $4-7$.

The bedding surfaces giving the surface aspect of the structures exhibited in the section, revealed best the character of the deformation (see also Dzulynski and Smith 1963). The irregularities are made up both of small single folds and of more complicated structures with high degree

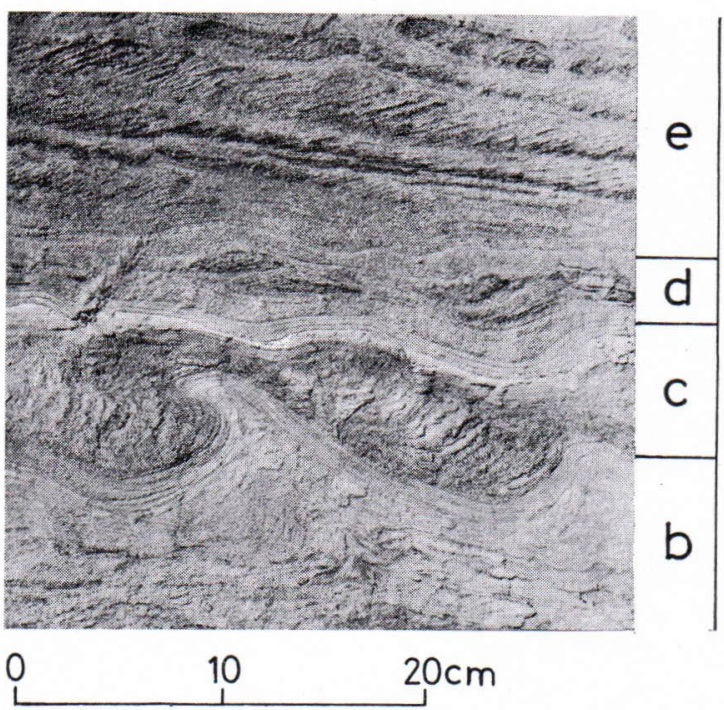

Fig. 7. A lacquer peel from the area at $0.7 \mathrm{~m}$ on the abscissa of the sketch. The deformation tongues, stronger than in Fig. 5. are dragged in the downcurrent direction. Current from right to left.

of crumpling. Single inclined bodies of sediment also exist with their dips varying up to 90 degrees, and in places there are structures resembling »slump» balls.

At 13.5-14 meters of the sketch, the units b and $\mathrm{c}$ are strongly distorted (Fig. 4). The section owes its configuration both to small scale deformation of laminae themselves and to the nearly vertical position of the beds. The high degree of deformation did not favour the decipherment of the causative process, but as the ripple-drift cross-lamination of the overlying $\mathrm{d}$ has adjusted to the deformative relief below, it can be deduced that the deformation took place before the deposition of unit $d$. The process is therefore syndepositional or metadepositional (see Nagtegaal 1963 , p. 366). The recumbent folds show horizontal movements.

The sands of unit d also show deformation. It is demonstrated by the oversteepened and overturned lees of the ripple-drift cross-lamination. Plastic sinking-squeezing movements could also be traced, but in this horizon no horizontal movements could be deduced. In the literature there are frequent observations of this 
kind of deformation from cross-bedded strata and it has been ascribed to current-drag during deposition (e.g. Kuenen 1953 b, p. 17; Sanders 1960; Einsele 1963; Potter and Pettijohn 1963). The change is transitional from the underlying high-degree deformation structures to those of units $\mathrm{d}$ to e above.

At $0.3 \mathrm{~m}$ and $1.0 \mathrm{~m}$ on the abscissa, the deformation is less intensive, and the mechanism of the process can be better deduced (Figs. 5-7). As in the undisturbed area of the section, the lamination of the fine sand in unit b shows here a passage from the type A ripple-drift crosslamination at the bottom into the gently undulating type, approaching the sinusoidal type, at the top. The undulating layer that is composed of slightly finer grain sizes bears deformation folds. Many of them are inclined and oriented approximately to the inferred direction of current flow from SSW $\left(180-220^{\circ}\right)$ to NNE. These rather gentle folds grade into more deformed recumbent folds and accompanying roll-up structures, which suggest more remarkable horizontal displacement (Fig. 6). Deformation has frequently taken place also in the laminae underlying some of the folds of the cohesive layer of fine material (Fig. 7). The small folds, often tongue-like, tend to be located on the domed crests of the underlying ripples which are mainly rather straight and uniform. This characteristic is recognizable from exposed bedding surface. The tongues visible in the photographs, therefore, are composite ripple - fold crests. A similar disposition of the fold crests over ripple crests has been described by Kuenen (op.cit.) and Dzulynski and Smith (1963, p. 624).

The base of unit $\mathrm{c}$ is sharp, suggesting a rather rapid change in the competence of the current at the unit b/unit $\mathrm{c}$ boundary. The first lee-side laminae at the base have chiefly been deposited in the shelter behind the compound ripple - fold crests of unit b. It indicates the existence of the deformed bottom relief prior to the first sandy lee's sedimentation on it. Many of these laminae which were deposited in the troughs were subsequently oversteepened and even overturned, and it indicates further that the deformation process continued upwards (Figs. 6 and 7). It took place throughout the sedimentation of the sands in unit c, but during the fallout phase of the veneer of fine material at the top of unit c, the velocity of the flow had slowed down, even being reversed (p. 167). The cohesive material then probably stabilized the bottom. A subsequent new deformation phase that occurred at the beginning of the deposition of unit $\mathrm{d}$, however, folded it in a way similar to that of the upper part of unit b.

The base of unit $d$ is not as sharp as that of unit c, but also shows a rather rapid acceleration of the flow velocity. The initial deformation occurred also in this case prior to the deposition of the overlying sediments, which adjusted to the underlying deformed bottom relief. Further deformation continued upwards with decreasing intensity, to die out gradually until at the top of the unit the laminae show no distortion. The fold crests and the first ripple crests were superimposed but the successive ripple crests, due to their asymmetry, were displaced in the direction of current flow (Fig. 5). Recumbent folds exist. Small scale irregular faults could be traced in the ripple-laminated sands from the time of the deformation process (see Holland 1959; Davies 1965, pp. 314-316).

Only slight deformation of syndepositional origin occurs above unit $\mathrm{d}$, and it mainly consists of oversteepened lee-side laminae of ripple-drift cross-lamination. Single sharp-peaked wisps of fine, squeezed-up material exist (Fig. 5), however, and resemble the often observed flame structures or mud wisps (e.g. Shrock 1948, p. 112; Sullwold 1959, 1960; Potter and Pettijohn 1963, p. 145; Sanders 1965, p. 198).

\section{Summary and conclusions}

The following data can be summarized from the above description to infer the origin of the deformation folds: 
- The initial deformation of the cohesive layers forming the tops of units $\mathrm{b}$ and $\mathrm{c}$ took place prior to the deposition of the overlying crosslaminated sands.

- The deformation continued upwards in the sand decreasing in intensity and dying out before the next layer of fines.

- The fold crests tend to be formed over ripple crests.

- The fold crests and the overlying successive ripple crests tend to be in superposition.

- The fold crests are often tilted in the downcurrent direction.

- The transition exists from the structures suggesting only vertical displacements to those indicative of more dominant horizontal movements.

The evidence shows that the deformational folds were formed by a syndepositional (in part metadepositional) process. Though the mechanism may be in part that connected with load folds (see e.g. Sullwold 1960; Nagtegaal 1963, p. 372; Dzulynski and Smith 1963, p. 624; Davies 1965), they will not be designated as such, since the initial deformation occurred prior to, and continued during, the deposition of the overlying sands. Structures, designated as load folds, are here attributed mainly to uneven loading of sediment by an overburden; accordingly they were developed after the deposition of the covering sediment. The nomenclature of these structures has been discussed by several workers (e.g. Kuenen 1953 a, b; Sullwold 1959, 1960; Holland 1960; Sanders 1960, p. 414; Potter and Pettijohn 1963). Varying usage exists in the designation, however, depending in part on the uncertainty in the inferred genesis. In many cases also at least two processes have operated together and no "either/or» choice can be made (see Dott and Howard 1962, p. 120). The load deformation by an overburden of covering sand is probably represented in the sequence studied by the sharp-peaked, squeezed-up structures of unit e (Fig. 5). They also, however, were formed closely concomitant with sedimentation (see e.g. Potter and Pettijohn 1963, p. 155).

The author puts the small folds of the Kiiminki section into the category of slight convolutions (see Kuenen 1953 b, pp. 14-21), caused mainly by drag effects of turbulent flow with differential pressure conditions, imposed on cohesive, hydroplastic material (see Shrock 1948; Kuenen 1953 b; Sanders 1960, 1965; Dzulynski and Smith 1963). It must be still taken into account that the deformation folds of Kiiminki were mainly formed over ripple crests, and further, that the anticlinal fold crests and the overlying ripple crests are superposed. These data fit well the explanation by rippling process (Kuenen 1953 b; see, however, also Holland 1959; Ten Haaf 1956, and Nagtegaal 1963, p. 371) when allowance has been made for the concept of the cohesive - cohesionless behaviour of fine grained sand (Sanders 1960). However, this mechanism seems to be applicable to only the small size folds of Kiiminki. Many other structures, such as the separate inclined blocks of sediment, the recumbent folds, piling up of sediments, the rolled-up balls, as well as some badly crumpled layers would obviously need another explanation (Dott and Howard 1962).

The following combination of causative processes and sequence of events is suggested: After the deposition of the cohesive layer at the top of unit b, a rapid increase of current velocity took place. The bottom responded to the increased shearing stress and the uneven distribution of pressure by developing the folds. Sanders considered these kinds of »streaked out ripples» to be the fine-grained sediment analogues to the current ripple-marks which occur only in coarse, cohesionless sediment (Sanders 1960; see also Dzulynski and Smith 1963, p. 622). The formation of the folds tended to be localized on ripple crests owing to the prevailing differential pressure conditions around the ripples (see Kuenen 1953 b, p. 18; Dzulynski and Smith 1963, p. 624). In this case the small deformation tongues were close to linguoidal in shape and they 
were formed over the crests of straight ripples; the shape of the folds and underlying ripples as well as their mutual position might be variable though (Dzulynski and Smith 1963, p. 624). In places the strong shearing by the current drag, in conjunction with the gravity-produced shearing stresses downslope in approximately the same direction, also induced horizontal displacements of various magnitude in the highly mobile hydroplastic layer. These movements are indicated by the asymmetry of the minute folds, as well as by the recumbent folds and higher degree crumpling and the roll-up structures resembling »slump» balls. There is a full gradation between structures derived from vertical displacements and those caused by horizontal movements, and no distinct boundary can be placed in the section studied between these two processes (see Ksiazkiewics 1958; Dzulynski, Ksiazkiewics and Kuenen 1959; Holland 1959; Dott and Howard 1962; Nagtegaal 1963, p. 373). The mechanism of this kind of horizontal movement has been thoroughly studied and discussed e.g. by Nagtegaal (op.cit.) and Davies (1965). A horizontal transition could also be traced from the deformation folds into undisturbed sediments (p. 164).

During the deposition of unit $\mathrm{c}$ the velocity slowed down and the intensity of deformation accordingly decreased with the decreasing drag effect. The cohesive - cohesionless behaviour of the material (Sanders 1960) probably played a part in the deformation mechanism of these sands. Further deformation did not occur during the deposition of fine material at the top of unit c.

The cycle of deformation was repeated when unit d was deposited. It also shows strongest deformation at the base with the intensity decreasing upwards with the decreasing current velocity. A transition from vertical to horizontal displacements exists also here, as inferred from the deformation structures.

The sandy material overlying these horizons mainly behaved non-cohesively, and the layers were not competent enough to be folded as a plastic unit. Some oversteepened and overturned laminae exist.

The references to structures similar to the small folds of Kiiminki relate mainly to turbidite rocks (e.g. Sanders 1960, p. 419; Kuenen 1953 b, p. 21). This holds also for the other kinds of structures designated as convolute lamination by different workers. In Kiiminki a Pleistocene glaciofluvial sequence is involved. As suggested by De Geer (1912) and Kuenen (1951) the hydrodynamic conditions in the glaciofluvial environment, however, must not necessarily differ significantly from those in the non-glacial turbidity flows. It seems also evident as suggested by Dott and Howard (1962, p. 119), that convolute lamination also exists in non-turbidite sequences (see also Emery 1950 and Einsele 1963). It must be further emphasized, that the designation "convolute lamination» refers to various kinds of morphological features as used in a broad sense by different workers. Further, the deformation products of many processes are often readily confused with each other, especially if a high degree of deformation is concerned. Hence, if "convolute lamination" is used in a broad morphological sense, or in a descriptive sense at all, it will be suspiciously polygenetic (see Dott and Howard 1962; Dzulynski and Smith 1963). The structures of Kiiminki designated as convolutions in this paper, accordingly only represent one type in the category. The same type is included in the description by Kuenen when the term »convolute bedding» was first suggested (Kuenen $1953 \mathrm{a}, \mathrm{b}$ ). The definition and the origin of convolute lamination has subsequently been thoroughly discussed in several papers (e.g. Ten Haaf 1956; Sanders 1960, 1965; Nagtegaal 1963; Einsele 1963; Potter and Pettijohn 1963; Dzulynski and Smith 1963; Davies 1965), so it will not be repeated again here.

Metadepositional horizontal movements designated as convolute lamination have been reported from Finland by M. Okko (1967) with a suggestion that they moriginated during the compaction of bed $\mathrm{C}$ under water through a gravity-induced 
rearrangement within the bed, leading to thixotropic behaviour» (see also Dott and Howard 1962; Nagtegaal 1963; Davies 1965). A mechanism of the same type possibly acted in combination with other processes in Kiiminki also, when the deformation structures were formed (p. 170).

Horizontal movements, which also may be metadepositional, have also been reported from Finnish Pleistocene sequences e.g. by Van Straaten (1949) and Aurola (1960), but in general these structures have not been much studied in Finland. In the author's experience, the type of structures described in this paper from Kiiminki, as well as the various other kinds having a syndepositional or metadepositional origin, are far more frequent in Finland than the literature would suggest.

These kinds of deformation structures seem to be rather common in the vicinity of Oulu (p. 163).
It is possibly related to the frequent occurrence of water-laid deposits composed of fine-grained sand and coarse silt, grain sizes liable to be deformed that way (see e.g. Ten Haaf 1956; Sanders 1960, p. 414; Einsele 1963; Nagtegaal 1963). In the study area, however, the conditions of ice-contact environment and the ice overrides of various age must also be considered (see Korpela 1969; R. Aario 1971). They are responsible for many kinds of deformation, which can readily be confused with some of the deformation structures of the above category. A careful and detailed examination is needed especially in this area, therefore, if the paleoenvironmental significance of the various structures is to be used in the geological interpretation.

Acknowledgements - The author is grateful for financial assistance given by the Science Research Council. He also wishes to express his thanks to Miss Lyn Powell, M. A. who kindly checked the English of the manuscript.

\section{REFERENCES}

Aario, Risto 1971, Consolidation of Finnish sediments by loading ice sheets. Bull. Geol. Soc. Finland 43.

Aario, Risto and Virtanen, Pentrir 1970, A lacquer film technique. Geologi 21, 1.

Aurola, Erkki 1960, Poimurakenteita Piispanristin sorakuopan seinämässä lähellä Turkua. Geologi 12, 3-4.

Davies, Huw G. 1965, Convolute lamination and other structures from the Lower Coal Measures of Yorkshire. Sedimentology 5 .

Dotr, JR. R. H. and Howard, J. K. 1962, Convolute lamination in non-graded sequences. Jour. Geol. 70, 1.

Dzulynski, S., Ksiazkiewicz, M. and Kuenen, PH. H. 1959, Turbidites in flysch of the Polish Carpathian Mountains. Bull. Geol. Soc. America 70, 8.

Dzulynski, S. and Smith, A. 1963, Convolute lamination, its origin, preservation, and directional significance. Jour. Sedim. Petr. 33, 3.

Ernsele, Gerhard 1963, „Convolute bedding» und ähnliche Sedimentstrukturen im rheinischen Oberdevon und anderen Ablagerungen. N. Jb. Geol. Paläont. 116, 2.

Emery, K. O. 1950, Contorted Pleistocene strata at Newport Beach, California. Jour. Sedim. Petr. 20, 2.

De GeER, G. 1912, A geochronology of the last 12000 years. C. R. 11. Congr. géol. intern. 1910.
Ten HaAf, ERnst 1956, Significance of convolute lamination. Geol. en Mijnbou 18, 6.

Holland, C. H. 1959, On convolute bedding in the Lower Ludlovian rocks of north-east Radnorshire. Geol. mag. 46.

- 1960, Load-cast terminology and origin of convolute bedding: some comments. Bull. Geol. Soc. America 71,5 .

Jopling, Alan and Walker, Roger 1968, Morphology and origin of ripple-drift cross-lamination, with examples from the Pleistocene of Massachusetts. Jour. Sedim. Petr. 38, 4.

Korpela, Kauko 1969, Die Weichsel-Eiszeit und ihr Interstadial in Peräpohjola (nördliches Nordfinnland) im Licht von submoränen Sedimenten. Ann. Acad. Sci. Fennicae A 99.

Ksiazkiewicz, M. 1958, Submarine slumping in the Carpathian flysch. Rocznik Polsk. Towarz. Geol. 28.

Kuenen, PH, H. 1951, Mechanics of varve formation and the action of turbidity currents. Geol. Fören. förh. $73,1$.

- 1953 a, Significant features of graded bedding. Bull. Am. Ass. Petr. Geol. 37.

- 1953 b, Graded bedding, with observations on Lower Paleozoic rocks of Britain. Verh. kon. ned. Akad. Wet. Amsterdam, Eerste reeks 20, 3. 
NagtegaAl, P. J. C. 1963, Convolute lamination, metadepositional ruptures and slumping in an exposure near Pobla de Segur (Spain). Geol. en Mijnbou 42, 11.

Oккo, Marjatta 1967, Convolute lamination in a late Pleistocene deposit at Pannujärvi, Tuulos, Finland. C. R. Soc. géol. Finlande 39.

Potter, P. and Petтrjohn, F. 1963, Paleocurrents and basin analysis. Berlin.

SANDERS, John, E. 1960, Origin of convoluted laminae. Geol. mag. 97, 5.

- 1965, Primary sedimentary structures and their hydrodynamic interpretation. Society of Economic Paleonto- logists and Mineralogists, Special Publication 12. 1965 Tulsa, Oklahoma U.S.A.

SHRock, Robert R. 1948, Sequence in layered rocks. New York.

Van Straaten, L. M. J. U. 1949, Occurrence in Finland of structures due to subaqueous sliding of sediments. Bull. Comm. géol. Finlande 144.

Sullwold, JR. H. H. 1959, Nomenclature of load deformation in turbidites. Bull. Geol. Soc. America 70.

- 1960, Load-cast terminology and origin of convolute bedding: further comments. Bull. Geol. Soc. America 71,5 .

Manuscript received, November 30, 1970. 